\title{
Risk Factors Predicting Mortality in Patients with Lung Abscess in a Public Tertiary Care Center in Karachi, Pakistan
}

\author{
Shaista Ghazal, ${ }^{1}$ Ashok Kumar, ${ }^{1}$ Binav Shrestha, ${ }^{2}$ Sana Sajid, ${ }^{1}$ Maria Malik, ${ }^{1}$ Nadeen Rizvi' \\ 'Department of Chest Medicine, Jinnah Postgraduate Medical Center, Karachi, Pakistan, ${ }^{2}$ Bolan Medical College, Quetta, \\ Pakistan.
}

\section{ABSTRACT}

Introduction: Lung abscess is a commonly encountered entity in South-East Asia but not much data regarding its outcome is available. The objective of this study was to identify the factors associated with increased mortality in patients diagnosed with lung abscess in a tertiary care center of Karachi, Pakistan.

Methods: A retrospective case analysis was performed via hospital records, on patients admitted with lung abscess between January 2009 and January 2011 at the largest state-owned tertiary care centre in Karachi, Pakistan. Out of the 41 patients hospitalized, 17 could not survive and were evaluated for clinical, radiological and microbiological factors to determine association with heightened mortality.

Results: Mortality due to lung abscess stood at $41.4 \%$ (17 of 41 cases). Adult male patients were found to have higher mortality with 13 out of 17 (43\%) dead patients being male. A majority (21/41, $51.2 \%$ ) of the cases belonged to the 41-60 year old age group. Highest mortality was seen in patients $<20$ years of age (3/4, 75\%). Patients with blood sugar levels of $>200 \mathrm{mg} / \mathrm{dL}$ (56\%) succumb to disease. Patients with a positive history of smoking, diabetes mellitus, and alcohol intake expressed mortality rates of $44 \%, 56 \%$, and $50 \%$ respectively; while $29.4 \%$ of the mortalities were positive for Pseudomonas aeruginosa on sputum culture. A significant association was found with elevated mortality and low haemoglobin levels at time of admission; mortality was $58 \%(p=0.005)$ in patients with $\mathrm{Hb}$ less than or equal to $10 \mathrm{mg} / \mathrm{dL}$.

Conclusions: The risk factors involved with heightened mortality included male gender and history of smoking, diabetes and alcohol intake. High blood sugar levels and detection of Pseudomonas aeruginosa on sputum cultures were also implicated. Anemia ( $\mathrm{Hb}$ level less than or equal to 10mg/ dl) was statistically significant predictive factor for increased mortality.

Keywords: lung abscess; mortality; risk factors.

\section{INTRODUCTION}

Lung abscess can be defined as a necrotic cavitary lesion of the lung parenchyma containing pus. ${ }^{1}$ Although lung abscess was found to have high mortality, 15 to $20 \%$, as shown in literature published in mid-eighties, ${ }^{2-5}$ due to advancement in diagnostic and therapeutic fields most recent data has shown a significant improvement in prognosis with mortalities not exceeding to more than $5 \% .^{1,6}$ Not much data regarding prognosis and outcome of lung abscesses diagnosed in South-east

Correspondence: Dr. Shaista Ghazal, Department of Chest Medicine, Jinnah Postgraduate Medical Center, Karachi, Pakistan. Email: mh_shaista@hotmail.com, Phone: +923321786737. 
Asia is available despite the fact that it is a commonly encountered entity here because it is a high incident area for respiratory illnesses. Studies from different parts of the world have shown that patients with lung abscess who are males, in higher age groups, immune deficient, anemic have poor prognosis especially those

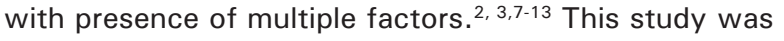
undertaken to see the factors which can be implicated in poor prognosis of patients diagnosed with lung abscess in Pulmonary Medicine department of one of the biggest public tertiary care centers of Pakistan.

\section{METHODS}

This is a retrospective study of 41 cases diagnosed with lung abscess admitted in Department of Chest Medicine of Jinnah Postgraduate Medical Center, Karachi, Pakistan from January 2009 to January 2011. These patients were diagnosed on the basis of clinical (fever, cough with sputum, hemoptysis, clubbing) and radiological findings (chest $\mathrm{x}$-ray showing cavitary lesion of lung parenchyma with air fluid level). A proforma was used to record demographics, comorbid conditions like diabetes, past history particularly of TB, smoking habit and laboratory data like hemoglobin $(\mathrm{Hb})$ levels, white cell count, sputum for AFB smear and routine culture of all these patients from hospital files. Data was entered and analyzed through SPSS version 17. Proportions and mean and standard deviation were calculated for categorical and continuous variables respectively. Chi square test and fisher exact was applied to assess association between risk factors and mortality in lung abscess.

\section{RESULTS}

Mean age of lung abscess patients in this study was found to be 44 years (SD 15 years) and 30 out of $41(73.2 \%)$ were males. Most common age group affected was between 41-60 years (51.2\%) followed by $20-40$ years $(29.3 \%)$. Among 41 sampled patients $17(41.4 \%)$ could not survive and rest $(58.5 \%)$ were discharged.

Among male patients, $17(57 \%)$ survived and among females seven (64\%) survived. Mortality was highest in patients younger than 20 years of age where three out of four $(75 \%)$ patients expired. Twenty seven patients $(65.9 \%)$ were smokers and six $(15 \%)$ were alcoholic (Table 1).
Table 1. Baseline characteristics of patients with lung abscess $(\mathrm{N}=41)$.

\begin{tabular}{|c|c|c|c|}
\hline Variables & $\begin{array}{l}\text { Total } n \\
(\%) \\
n=41 \\
\text { Mean } \pm \text { SD }\end{array}$ & $\begin{array}{l}\text { n (\%) } \\
\text { Discharged }\end{array}$ & $\begin{array}{l}\text { n (\%) } \\
\text { Expired }\end{array}$ \\
\hline Age (years) & $44 \pm 15.9$ & & \\
\hline$<20$ & $4(10)$ & $1(25)$ & $3(75)$ \\
\hline $20-40$ & 12 (29) & $8(67)$ & 4 (33) \\
\hline $41-60$ & $21(51)$ & $12(57)$ & 9 (43) \\
\hline$>60$ & $4(10)$ & $3(75)$ & $1(25)$ \\
\hline \multicolumn{4}{|l|}{ Sex } \\
\hline Male & $30(73)$ & $17(57)$ & $13(43)$ \\
\hline Female & $11(27)$ & 7 (64) & $4(36)$ \\
\hline \multicolumn{4}{|c|}{ History of smoking } \\
\hline Yes & $27(66)$ & $15(56)$ & $12(44)$ \\
\hline No & $14(34)$ & 9 (64) & $5(36)$ \\
\hline \multicolumn{4}{|c|}{ History of sinusitis } \\
\hline Yes & $11(27)$ & $5(55)$ & $6(45)$ \\
\hline No & $30(73)$ & 19 (63) & 11 (37) \\
\hline \multicolumn{4}{|c|}{ History of alcohol intake } \\
\hline Yes & $6(15)$ & $3(50)$ & $3(50)$ \\
\hline No & $35(85)$ & $21(60)$ & $14(40)$ \\
\hline \multicolumn{4}{|c|}{ History of diabetes } \\
\hline \multirow[t]{2}{*}{$\begin{array}{l}\text { Yes } \\
\text { No }\end{array}$} & $18(44)$ & $8(44)$ & $10(56)$ \\
\hline & $23(56)$ & $16(70)$ & $7(30)$ \\
\hline \multicolumn{4}{|c|}{ History of tuberculosis } \\
\hline \multirow{2}{*}{$\begin{array}{l}\text { Yes } \\
\text { No }\end{array}$} & 16 (39) & 11 (69) & $5(31)$ \\
\hline & $25(61)$ & $13(52)$ & $12(48)$ \\
\hline \multicolumn{4}{|l|}{ Hb level } \\
\hline$<7$ & $4(10)$ & $2(50)$ & $2(50)$ \\
\hline $7-10$ & $22(54)$ & $9(41)$ & $13(59)$ \\
\hline$>10$ & $15(36)$ & 13 (87) & 2 (13) \\
\hline
\end{tabular}

On analysis of complete blood count in these patients it was observed that significant relationship ( $p$-value $0.005)$ existed between anemia $(\mathrm{Hb} \leq 10 \mathrm{mg} / \mathrm{dl})$ and mortality. There were $26(63 \%)$ patients with $\mathrm{Hb}$ level equal to or less than $10 \mathrm{mg} / \mathrm{dl}$ out of whom 15 $(58 \%)$ expired. Surprisingly history of TB or presence of active TB was not revealed as a significant factor (p-value 0.34) among these patients. There were 16 $(39 \%)$ patients who gave history of tuberculosis out of whom five (31\%) expired. History of smoking, alcohol, diabetes were insignificant risk factors affecting survival 
in our study (Table 2).

Table 2. Associations of risk factors with mortality among lung abscess patients $(n=41)$.

\begin{tabular}{|c|c|c|c|c|}
\hline Variables & $\begin{array}{l}n(\%) \\
\text { Total }(n=41)\end{array}$ & $\begin{array}{l}\text { n (\%) } \\
\text { Discharged }\end{array}$ & $\begin{array}{l}\text { n (\%) } \\
\text { Expired }\end{array}$ & P-value \\
\hline \multicolumn{5}{|c|}{ SOCIO-DEMOGRAPHIC FACTORS } \\
\hline $\begin{array}{l}\text { Age (years) } \\
\leq 40 \text { years } \\
>40 \text { years }\end{array}$ & $\begin{array}{l}16(39) \\
25(61)\end{array}$ & $\begin{array}{l}9(56) \\
15(60)\end{array}$ & $\begin{array}{l}7(44) \\
10(40)\end{array}$ & 0.81 \\
\hline $\begin{array}{l}\text { Sex } \\
\text { Male } \\
\text { Female }\end{array}$ & $\begin{array}{l}30(73) \\
11(27)\end{array}$ & $\begin{array}{l}17(57) \\
7(64)\end{array}$ & $\begin{array}{l}13(43) \\
4(36)\end{array}$ & 0.73 \\
\hline \multicolumn{5}{|c|}{ PAST HISTORY AND FAMILY HISTORY } \\
\hline $\begin{array}{l}\text { History of smoking } \\
\text { Yes } \\
\text { No }\end{array}$ & $\begin{array}{l}27(66) \\
14(34)\end{array}$ & $\begin{array}{l}15(56) \\
9(64)\end{array}$ & $\begin{array}{l}12(44) \\
5(36)\end{array}$ & 0.59 \\
\hline $\begin{array}{l}\text { History of alcohol intake } \\
\text { Yes } \\
\text { No }\end{array}$ & $\begin{array}{l}6(15) \\
35(85)\end{array}$ & $\begin{array}{l}3(50) \\
21(60)\end{array}$ & $\begin{array}{l}3(50) \\
14(40)\end{array}$ & 0.67 \\
\hline $\begin{array}{l}\text { History of diabetes } \\
\text { Yes } \\
\text { No }\end{array}$ & $\begin{array}{l}18(44) \\
23(56)\end{array}$ & $\begin{array}{l}8(44) \\
16(70)\end{array}$ & $\begin{array}{l}10(56) \\
7(30)\end{array}$ & 0.12 \\
\hline $\begin{array}{l}\text { History of tuberculosis } \\
\text { Yes } \\
\text { No }\end{array}$ & $\begin{array}{l}16(39) \\
25(61)\end{array}$ & $\begin{array}{l}11(69) \\
13(52)\end{array}$ & $\begin{array}{l}5(31) \\
12(48)\end{array}$ & 0.34 \\
\hline LABORATORY FINDING & & & & \\
\hline $\begin{array}{l}\text { Hb level (mg/dl) } \\
\leq 10 \\
>10\end{array}$ & $\begin{array}{l}26(63) \\
15(37)\end{array}$ & $\begin{array}{l}11(42) \\
13(87)\end{array}$ & $\begin{array}{l}15(58) \\
2(13)\end{array}$ & 0.005 \\
\hline $\begin{array}{l}\text { TLC level } \\
\leq 11 \\
>11\end{array}$ & $\begin{array}{l}14(34) \\
27(66)\end{array}$ & $\begin{array}{l}9(64) \\
15(56)\end{array}$ & $\begin{array}{l}5(36) \\
12(44)\end{array}$ & 0.59 \\
\hline
\end{tabular}

RBS level
$\leq 200$
$>200$
17 (68)

$7(44)$
$8(32)$

$9(56)$

\section{DISCUSSION}

This study shows that lung abscess continues to exhibit high mortality as observed in previous studies. ${ }^{2-5}$ Although there has been some recent data to suggest decline in mortality, ${ }^{1,6}$ our finding does not correlate with the observation. The reason for this high mortality can be many folds ranging from socio-economic factors, late presentation to the hospital, presence of comorbidities etc. It has been described in various studies that patients with multiple risk factors show poor prognosis as compared to those with single or none..$^{2,3,7-11}$ Similar observation has been made in the study by Perlman et al with mortality reaching to $75 \%$ in patients with predisposing factors. ${ }^{9}$ Our study 
corroborates with this observation. Mortality in our analysis was found to be quite high $(41.4 \%)$ affecting male gender more than females. Although reason of high mortality in this case can be explained on the basis that lung abscess itself was found to be more common in this group. Hirshberg, ${ }^{2}$ Solh et $\mathrm{al}^{12}$ and $\mathrm{Ai}-\mathrm{His} \mathrm{Hsu}$ et $\mathrm{al}^{13}$ show similar observation in their study. Data published by $\mathrm{Ai}-\mathrm{His} \mathrm{Hsu}$ et al, ${ }^{13}$ shows $14 \%$ mortality with male predominance (86\%) in an analysis of 123 patients diagnosed as having lung abscess.

An important factor observed in the analysis was history of smoking with $44 \%$ of the expired population being smokers. History of chronic smoking has been found in previous studies; $57.5 \%$ in data published by Bhattacharyya et al, ${ }^{14}$ while Hirsberg, ${ }^{2}$ had $37 \%$ patients with COPD in his analysis. Studies done in Japan and Taiwan had $75 \%,{ }^{15}$ and $57 \%,{ }^{16}$ smokers respectively with lung abscess in their studies. In all these studies, relation to mortality was not studied.

Diabetes mellitus has been reported as a recognized predisposing factor of lung abscess in various studies, $4,13,15,16$ incidence of diabetes was found to be $44 \%$ in our study making $56 \%$ of the expired group. Diabetes was found to be present in $31 \%$ patients of lung abscess in findings published by Wang et al, ${ }^{16}$ $37 \%$ in patients with complicated abscess in a study done in Taiwan, ${ }^{13} 22.9 \%$ among Japanese patients. ${ }^{15}$ Although diabetes was found to be most common risk factor among patients of lung abscess in Taiwan, it was not shown to have any relation to mortality as only two patients died during admission, ${ }^{13}$ which is in contrast with our observation (10 out of 18 diabetics expired). Other studies have not reported any relation to mortality among diabetics with lung abscess.

Another observation was high mortality among those patients who had raised blood sugar levels at admission whether known diabetics or not (56\%). Raised sugars can be representative of severe infection leading to death in these patients.

Use of alcohol has been found to be associated with increased incidence of lung abscess through many studies, ${ }^{1,4,13-17}$ as it impairs immunity, ${ }^{4,17-19}$ and also because alcohol users are prone to vomit which can lead to aspiration. ${ }^{4}$ The incidence is reported as $67 \%$ in an analysis of 50 cases by Robert L Hackney, ${ }^{17}$ $19 \%$ in study by Hagan, ${ }^{4} 70.2 \%$ in an study done on cases diagnosed from 1968 to 2004 in Brazil, ${ }^{1} 30 \%$ in simple abscesses in Taiwan diagnosed from 1990 to 2003. ${ }^{13}$ Most recent data in this regard is published by Bhattacharyya with $22.5 \%$ alcohol users, ${ }^{14}$ and $16.6 \%$ in a study from Japan. ${ }^{15}$ These results are in accordance with our findings showing $15 \%$ patients having history of alcohol use though this figure may not be accurate as many patients hesitate in admitting the use of alcohol in Pakistan. Among those who expired, 50\% were found to be alcohol users in this analysis. Despite being found as a common predisposing factor, effect of alcohol on mortality has not been documented in literature so this result cannot be evaluated in light of findings in other studies.

It was observed that $23 \%$ of the diagnosed cases were found to have active TB while $39 \%$ had history of TB in past. Among expired group, 17.6\% (3/17 patients) had active TB while $31 \%$ (5/17) reported to have previous TB. A study from South Africa on 34 patients with lung abscess revealed seven ( $21 \%$ ) having tuberculous lung abscess diagnosed via percutaneous lung aspiration and protected specimen brush through fibreoptic bronchoscopy. ${ }^{20}$ Many patients were reported to have chest $\mathrm{X}$-ray features compatible with past $\mathrm{TB}^{20}{ }^{20}$ similar results have been reported in Singapore $(21 \%)$ and Hong Kong $(12 \%)$ reflecting high incidence of tuberculous abscess in Asia. ${ }^{21-23}$ In the analysis by Bhattacharya, ${ }^{14}$ incidence of TB in lung abscess patients was reported to be $25 \%$ ( 30 patients of 120 ) out of whom 18 were diagnosed by sputum for AFB smear and rest through BAL fluid smear and culture. Disease outcome was not included in the analysis. ${ }^{14}$

Our study shows comparable result for incidence of TB in lung abscess but mortality is comparatively higher in these patients compared to South African study, ${ }^{20}$ where only single death was reported out of 34 patients. Since only AFB smear of sputum was taken into account as sputum for AFB culture, results were not available and more invasive techniques were not performed for diagnosis, the incidence of TB and reported mortality may have been higher than what was observed in this analysis, taking into consideration the high incidence of TB in Pakistan.

The results of sputum culture showed a wide range of organism with Pseudomonas aeruginosa being the most common one (29.3\%). Among expired group this was also the most common pathogen $(5 / 17,29.5 \%)$ which is in concordance with the obseravation made by Hirshberg et al. ${ }^{2}$

This study shows anemia to be a significant risk factor predicting moratlity in lung abscess pateints ( $p$-value 0.005). Similar observation was made by Hirshberg et al, showing higher mortality in patients with $\mathrm{Hb}$ level < $10 \mathrm{mg} / \mathrm{dl}$ on admission ( $p=0.0008$ ) although, as also noticed by Hirsberg, this can be due to poor underlying 
condition of the patient leading to higher mortality. ${ }^{2}$

The major weakness of the study was that it was a retrospective observation of cases admitted in our hospital over a period of two years to see the trends in lung abscess patients in relation to mortality in this part of world. Prospective studies need to be done to better understand the causative factors responsible for high mortality in lung abscess cases so that they can be addressed appropriately.

\section{CONCLUSIONS}

From the present study it is concluded that male gender, history of diabetes and smoking, high blood sugar level at presentation and presence of Pseudomonas aeruginosa on sputum culture are important risk factors predicting mortality in patients with lung abscess. $\mathrm{Hb}$ level of less than or equal to $10 \mathrm{mg} / \mathrm{dL}$ was found to be a statistically significant predictive factor for increased mortality with a P-value $<0.005$.

\section{REFERENCES}

1. Moreira JdS, Camargo JdJP, Felicetti JC, Goldenfun PR, Moreira ALS, Porto NdS. Lung abscess: analysis of 252 consecutive cases diagnosed between 1968 and 2004. Jornal Brasileiro de Pneumologia. 2006;32(2):136-43.

2. Hirshberg B, Sklair-Levi M, Nir-Paz R, Ben-Sira L, Krivoruk $\mathrm{V}$, Kramer MR. Factors predicting mortality of patients with lung abscess. Chest. 1999 Mar;115(3):746-50.

3. Harber P, Terry PB. Fatal lung abscesses: review of 11 years' experience. Southern Medical Journal. 1981;74(3):281-3.

4. Hagan JL, Hardy JD. Lung abscess revisited. A survey of 184 cases. Annals of Surgery. 1983;197(6):755.

5. Pohlson EC, McNamara JJ, Char C, Kurata L. Lung abscess: a changing pattern of the disease. The American journal of surgery. 1985;150(1):97-101.

6. Kioumis I, Bouros D. The microbiology of bacterial lung abscess: time for a reappraisal? Respiration. 2010;80(2):96-7.

7. JG B. Lung abscess. In: Baum GL WE, editor. Textbook of pulmonary diseases. 5th ed. Boston, MA: Little,Brown and Company; 1994. p. 607-20.

8. Bartlett JG. Anaerobic bacterial infections of the lung and pleural space. Clinical infectious diseases. 1993;16(Supplement 4):S248-S55.

9. Perlman L, Lerner E, D'esopo N. Clinical classification and analysis of 97 cases of lung abscess. The American review of respiratory disease. 1969;99(3):390.

10. Mori T, Ebe T, Takahashi M, Isonuma H, Ikemoto H, Oguri T. Lung abscess: analysis of 66 cases from 1979 to 1991. Internal medicine (Tokyo, Japan). 1993 Apr;32(4):278-84.

11. Chidi C, Mendelsohn H. Lung abscess. A study of the results of treatment based on 90 consecutive cases. The Journal of thoracic and cardiovascular surgery. 1974;68(1):168.

12. El-Solh AA, Pietrantoni C, Bhat A, Aquilina AT, Okada M, Grover $\mathrm{V}$, et al. Microbiology of severe aspiration pneumonia in institutionalized elderly. American journal of respiratory and critical care medicine. 2003 Jun 15;167(12):1650-4.
13. Hsu A-H, Lee J-J, Yang G-G. Prognostic Factors Predicting Mortality in Lung Abscess, 154 Cases Analysis. Tzu Chi Medical Journal. 2005;17(1):11-6.

14. Bhattacharyya SK, Mandal A, Thakur SB. Clinico-radiological profile of lung abscess: analysis of 120 cases. International Journal of Medicine and Medical Sciences. 2010;2(7):222-5.

15. Takayanagi N, Kagiyama N, Ishiguro T, Tokunaga D, Sugita Y. Etiology and outcome of community-acquired lung abscess. Respiration. 2010;80(2):98-105.

16. Wang J-L, Chen K-Y, Fang C-T, Hsueh P-R, Yang P-C, Chang $\mathrm{S}-\mathrm{C}$. Changing bacteriology of adult community-acquired lung abscess in Taiwan: Klebsiella pneumoniae versus anaerobes. Clinical infectious diseases. 2005;40(7):915-22.

17. Hackney Jr RL, Contee R. Lung abscess--an analysis of 50 cases. Journal of the National Medical Association. 1971;63(1):6

18. Green L, Green G. Differential suppression of pulmonary antibacterial activity as the mechanism of selection of a pathogen in mixed bacterial infection of the lung. The American review of respiratory disease. 1968;98(5):819.

19. Brayton RG, Stokes PE, Schwartz MS, Louria DB. Effect of alcohol and various diseases on leukocyte mobilization, phagocytosis and intracellular bacterial killing. The New England journal of medicine. 1970 Jan 15;282(3):123-8.

20. Hammond JM, Potgieter PD, Hanslo D, Scott H, Roditi D. The etiology and antimicrobial susceptibility patterns of microorganisms in acute community-acquired lung abscess. CHEST Journal. 1995;108(4):937-41.

21. Chan C, Cohen M, Pang J. A prospective study of community-acquired pneumonia in Hong Kong. CHEST Journal. 1992;101(2):442-6.

22. Prout S, Potgieter P, Forder A, Moodie J, Matthews J. Acute community-acquired pneumonias. S Afr Med J. 1983;64(12):443-6.

23. Hui KP, Tan WC, Chan TB, Chin NK. Community-acquired Pneumonia in the Far East. CHEST Journal. 1993;103(5):1637 